Check for updates

Cite this: RSC Adv., 2018, 8, 59

Received 18th October 2017

Accepted 8th December 2017

DOI: 10.1039/c7ra11520b

rsc.li/rsc-advances

\section{Highly efficient removal of sulfuric acid aerosol by a combined wet electrostatic precipitator}

\author{
Zhengda Yang, Chenghang Zheng, (D) X Xuefeng Zhang, Qianyun Chang, \\ Weiguo Weng, Yi Wang and Xiang Gao (D)*
}

Eliminating sulfuric acid aerosol from flue gas is of vital importance to improve air quality. In this paper, a wet electrostatic precipitator (WESP) assisted with novel pre-charger was proposed to efficiently remove sulfuric acid aerosol. Parameters including residence time, gas temperature and $\mathrm{SO}_{3}$ concentration were studied to find the key factors influencing sulfuric acid aerosol removal. Results showed that the removal efficiency of sulfuric acid aerosol increased with the increasing residence time and the decreasing gas temperature. The maximum corona current was reduced from 0.79 to $0.28 \mathrm{~mA}$ when the $\mathrm{SO}_{3}$ concentration increased from 0 to $25 \mathrm{ppm}$, and the removal efficiency also decreased with the increasing $\mathrm{SO}_{3}$ concentration. A novel perforated pre-charger was designed to improve the WESP performance for sulfuric acid aerosol removal. With assistance of the pre-charger, the removal efficiency was improved from 90.3 to $95.8 \%$, and the corresponding emission concentration was lower than $2 \mathrm{mg} \mathrm{m}^{-3}$. Moreover, the removal efficiency could be further improved to $97.8 \%$ with a heat exchanger, and the corresponding emission concentration could be lower than $1 \mathrm{mg} \mathrm{m}^{-3}$.

\section{Introduction}

Sulfuric acid aerosol from coal-fired power plants gains increasing attention because it can lead to a variety of plant operation problems such as air heater plugging and fouling, back-end corrosion, and plume opacity. ${ }^{1-3}$ As a consequence, emissions of sulfuric acid aerosol are required to meet extremely rigid standards in countries such as United States and Germany. In China, the local standard of Shanghai requires the emission of sulfuric acid mist $<5 \mathrm{mg} \mathrm{m}^{-3}$.

In coal-fired power plants, the formation of sulfuric acid aerosol comes from the combination of $\mathrm{SO}_{3}$ with flue gas moisture. During combustion process in the boiler, a part of sulfur in fuels can be oxidized to gaseous $\mathrm{SO}_{3}$. The $\mathrm{SO}_{3}$ concentration increases significantly after selective catalytic reduction (SCR) system because $0.25-1.25 \%$ of $\mathrm{SO}_{2}$ can be converted to $\mathrm{SO}_{3} \cdot{ }^{1,5,6}$ When the flue gas enters into the wet flue gas desulfurization (WFGD), the flue gas temperature can be easily quenched to below $50{ }^{\circ} \mathrm{C}$, and correspondingly saturated gas condition is established. ${ }^{7,8}$ During this process, gaseous $\mathrm{SO}_{3}$ will combine with $\mathrm{H}_{2} \mathrm{O}$ molecules to form sulfuric acid aerosol. The sulfuric acid aerosol is too small to be efficiently captured by WFGD. ${ }^{5}$ Heterogeneous vapor condensation method can be used to enlarge the aerosol size and improve the removal

State Key Lab of Clean Energy Utilization, State Environmental Protection Engineering Center for Coal-Fired Air Pollution Control, Institute for Thermal Power Engineering, Zhejiang University, 38 Zheda Road, Hangzhou 310027, China. E-mail: zhengch2003@zju.edu.cn; xgao1@zju.edu.cn; Fax: +86-571-87953129, +86-57187951616; Tel: +86-571-87953129, +86-571-87951335 efficiency of WFGD. However, the removal efficiency is still less than $70 \%$ and the emission of mass concentration is more than $15 \mathrm{mg} \mathrm{m}{ }^{-3}$. ${ }^{9}$ Once sulfuric acid aerosol is discharged from the stack without further control methods, the stack is typically featured as bluish plume and human health will be endangered particularly when burning high sulfur content coal. As a possible countermeasure, WESP is installed downstream of WFGD to control fine dust particles and carryover of slurry droplets, which can simultaneously eliminate the emission of sulfuric acid aerosol. ${ }^{2}$

WESP removes fine particles including sulfuric acid aerosols electrostatically with high removal efficiency, and the stack plume condition will be significantly improved. Inside a WESP, flue gas is ionized by high voltage to produce ions and electrons. When sulfuric acid aerosol enters WESP, it is negatively charged as a result of field charging and diffusion charging effects. Field charging is dominant for aerosols larger than $1.0 \mu \mathrm{m}$, and diffusion charging contributes more for aerosols less than $1.0 \mu \mathrm{m} .{ }^{10}$ The charged aerosols are driven by electric force to move towards collection plates and emerge into liquid film. ${ }^{\mathbf{1 1 - 1 4}}$ The removal efficiency of sulfuric acid aerosol by WESP is much higher than WFGD. ${ }^{15}$ The removal efficiency increased with the increasing of specific surface area (SCA) and electric field intensity. ${ }^{16}$ Nevertheless, WESP may suffer with efficiency reduction when dealing with gases with high $\mathrm{SO}_{3}$ concentrations. ${ }^{5}$ Generally, small size of sulfuric acid mist is the primary factor limiting efficient separation from flue gases. Some agglomeration technologies, i.e., acoustic agglomeration, electrical agglomeration and chemical agglomeration, ${ }^{\mathbf{1 7 - 2 0}}$ are 
possible solutions to improve fine particle removal efficiency by enlarging particle size. However, all these technologies are only implemented before dry ESP or before WFGD. Additionally, some researchers pointed out that separation efficiency of fine particle can be improved by electrostatic pre-treatment methods. Multi-field WESP is an easiest way to improve the removal efficiency. ${ }^{21}$ Chang et al. proposed a bipolar charger to agglomerate particles with water droplet humidification. ${ }^{20}$ Kim et al. developed a novel two-stage WESP which used a carbon brush pre-charger to increase the removal performance for ultrafine particles. ${ }^{22}$ Their results showed that electrostatic pre-treatment combined with WESP can be a costeffective method to improve the removal efficiency.

Enhanced methods are widely used to improve fine particle removal efficiency, while mineral work reports on the improvement of WESP performance for sulfuric acid aerosol removal. In this study, a horizontal WESP experimental system was designed to investigate the removal of sulfuric acid aerosol under simulated flue gas condition. The aerosol size distribution was measured to study the sulfuric acid aerosol formation characteristics before WESP. Influences of residence time, gas temperature and $\mathrm{SO}_{3}$ concentration on removal efficiency were investigated experimentally without any enhanced methods. On this basis, a novel perforated pre-charger was carefully constructed to improve removal efficiency of sulfuric acid aerosol. With the assistance of a pre-charger and a heat exchanger, various emission requirements can be satisfied.

\section{Experimental setup and methods}

\subsection{Experimental setup}

A schematic of the experimental system is illustrated in Fig. 1. The system consists of five sections, namely, $\mathrm{a} \mathrm{SO}_{3}$ generator, a wet flue gas desulfurization (WFGD), a heat exchanger, a labscale horizontal WESP with high frequency power supply source, and a sulfuric acid aerosol sampling and analysis system.

The cross section of the WESP was rectangular $(120 \mathrm{~mm} \times$ $300 \mathrm{~mm}$ ), and the length of the WESP was $1200 \mathrm{~mm}$. The discharge electrode was consisted of 10 wires placed with an interval of $10 \mathrm{~mm}$, and the distance between discharge electrode and collection plate was $60 \mathrm{~mm}$. Two Teflon insulators were used to fix the discharge electrodes in the center of the WESP. To ensure the insulating properties at saturation gas condition, the insulator surface was heated by an electric heater. A high frequency power supply $(50 \mathrm{kV}, 2 \mathrm{~mA}, 20 \mathrm{kHz}$, and negative DC) was connected with the discharge electrode to generate corona ions. A pre-charger was installed at the inlet of the WESP and was configured with spike-wires and two air distribution plates. Another power supply $(40 \mathrm{kV}, 2 \mathrm{~mA}, 20 \mathrm{kHz}$, and negative DC) was connected with the pre-charger to generate strong electric field and produce high density ions.

The contaminated flue gas was simulated by introducing $\mathrm{SO}_{3}$ into main gas stream. A fan was used to provide the main gas with maximum flow rate of $140 \mathrm{~m}^{3} \mathrm{~h}^{-1}$. An electric heater with maximum electric power of $20 \mathrm{~kW}$ was used to heat the air to set temperatures $\left(90-120{ }^{\circ} \mathrm{C}\right)$. An S-type thermal couple was installed at the exit of the electric heater to measure the gas temperature and fed back the temperature to the controller to adjust the heating power. All gas pipes were covered with thermal insulation material to reduce heat loss. The hot gas was scrubbed by a WFGD tower, resulting in significant drop of gas temperature to about $45{ }^{\circ} \mathrm{C}$. Consequently, a saturation, or even super-saturation gas condition pre-existed before entering the WESP.

$\mathrm{SO}_{3}$ was produced by an $\mathrm{SO}_{3}$ generator and was completely converted to sulfuric acid aerosols by nucleation during WFGD process. The $\mathrm{SO}_{3}$ generator worked on the principle of $\mathrm{SO}_{2}$ oxidation catalyzed with vanadium pentoxide $\left(\mathrm{V}_{2} \mathrm{O}_{5}\right)$. The catalyst reactor was maintained at approximately $410{ }^{\circ} \mathrm{C}$ to promote $\mathrm{SO}_{3}$ conversion efficiency. An $\mathrm{SO}_{2}$ gas analyzer was used to measure the $\mathrm{SO}_{2}$ concentration, and the conversion efficiency from $\mathrm{SO}_{2}$ to $\mathrm{SO}_{3}$ was supposed to be as high as $100 \%$ since no residual $\mathrm{SO}_{2}$ was detected at the exist of the generator.

\subsection{Experimental approach}

The removal of sulfuric acid aerosol was investigated under different parameters (i.e. applied voltage, residence time, gas temperature and $\mathrm{SO}_{3}$ concentration). The applied voltage of the WESP varied from 12 to $36 \mathrm{kV}$ by adjusting the power supply.

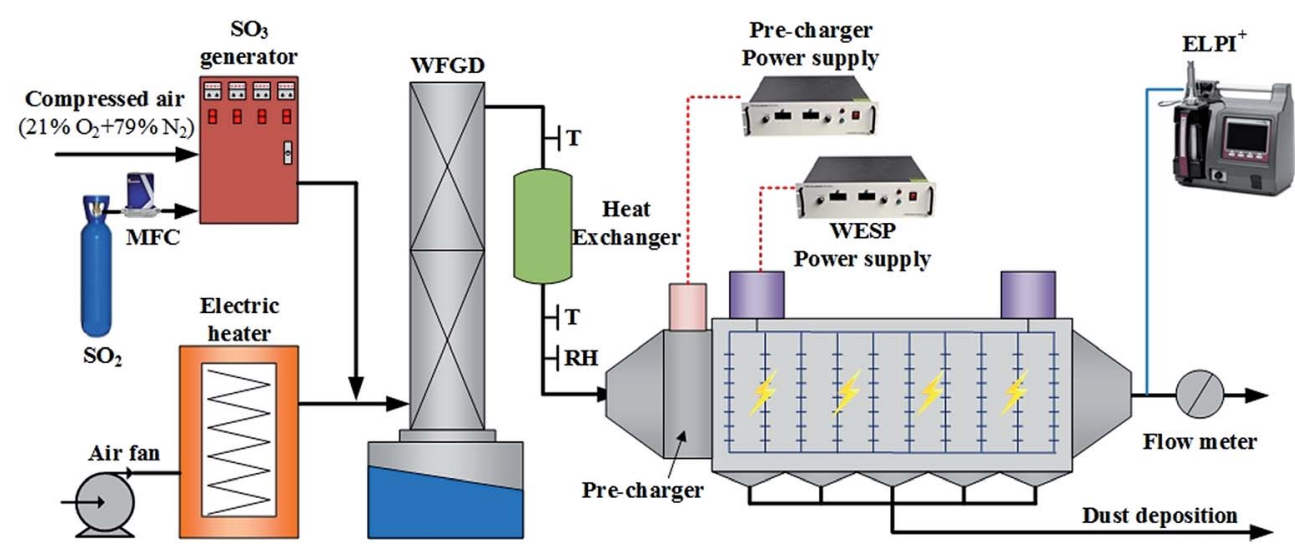

Fig. 1 Schematic of the experimental system. 
The residence time varied from 1.1 to $2.6 \mathrm{~s}$ by changing the total gas flow rate. The gas temperature after the gas heater varied from 90 to $120{ }^{\circ} \mathrm{C}$ by adjusting the electric power. The $\mathrm{SO}_{3}$ concentration varied from 5 to 25 ppm by adjusting the $\mathrm{SO}_{2}$ mass flow controller.

Sulfuric acid aerosol is fine droplet of sulfuric acid solution. It cannot be measured with off-line weighing method by collecting it on impactors or films. An on-line device of electrical low pressure impactor (ELPI ${ }^{+}$, Dekati Ltd., Finland) was used to measure the concentration of sulfuric acid aerosol with different diameters. It works on the principle of induced current method. The aerosol is charged to known charge level in a unipolar corona charger and then classified into different stages depending on aerosol diameters. The current on each stage is detected by sensitive electrometer, the signal of which is inverted to calculate aerosol number concentrations. The sampling gas flow rate of the $\mathrm{ELPI}^{+}$is $10 \mathrm{~L} \mathrm{~min}^{-1}$, generated by a vacuum pump. The number concentration of sulfuric acid aerosol can be higher than $1 \times 10^{8} \mathrm{~cm}^{-3}$, and a diluter (Diluter DI-1000, Dekati Ltd., Finland) was used to dilute the gas with clean air. Reducing gas temperature can lead to the growing of sulfuric acid aerosol by condensation, thus the probe was heated to the same temperature with the flue gas to ensure the sampling accuracy.

The WESP performance for the removal of sulfuric acid aerosol was evaluated by the fractional and total removal efficiencies, which can be calculated by the following equations, respectively:

$$
\begin{gathered}
\eta_{i}(\%)=\frac{N_{\text {out }, \text { off }}\left(r_{i}\right)-N_{\text {out }, \text { on }}\left(r_{i}\right)}{N_{\text {out }, \text { off }}\left(r_{i}\right)} \times 100 \% \\
\eta_{\text {total }}(\%)=\frac{\sum m_{\text {out }, \text { off }}\left(r_{i}\right)-\sum m_{\text {out }, \text { on }}\left(r_{i}\right)}{\sum m_{\text {out }, \text { off }}\left(r_{i}\right)} \times 100 \%
\end{gathered}
$$

where $N_{\text {out,on }}\left(r_{i}\right)$ and $N_{\text {out,off }}\left(r_{i}\right)$ denote fractional particle number concentrations $\left(1 \mathrm{~cm}^{-3}\right)$ with and without corona discharge, respectively. $m_{\text {out,on }}\left(r_{i}\right)$ and $m_{\text {out,off }}\left(r_{i}\right)$ denote fractional particle mass concentrations $\left(\mathrm{mg} \mathrm{m}^{-3}\right)$ with and without corona discharge, respectively. $\eta_{i}(\%)$ and $\eta_{\text {total }}(\%)$ are the fractional and total collection efficiencies, respectively.

\section{Results and discussion}

\subsection{Size distribution of sulfuric acid aerosol}

The concentration evolution of sulfuric acid aerosol with different diameters is shown in Fig. 2a. The system operated with constant $\mathrm{SO}_{3}$ concentration of $10 \mathrm{ppm}$. The circulating water came to spray approximately at $80 \mathrm{~s}$ and the concentration of sulfuric acid aerosol increased significantly. The total number concentration increased from about $5 \times 10^{7}$ to higher than $1 \times 10^{8} \mathrm{~cm}^{-3}$. Sulfuric acid aerosol was supposed to be removed by WFGD, whereas the number concentration increased after WFGD. The reason can be attributed to that $\mathrm{SO}_{3}$ was injected into the flue gas before WFGD. Only a part of gaseous $\mathrm{SO}_{3}$ formed sulfuric acid aerosol before scrubbing. When the WFGD came into operation, a part of sulfuric acid aerosol was removed while new sulfuric acid aerosol was formed during this process. Size distributions of sulfuric acid aerosol at the inlet and outlet of WFGD are compared in Fig. 2b. As can be seen, diameters of sulfuric acid aerosol are mainly smaller than $0.1 \mu \mathrm{m}$ for both two cases. The number concentration for aerosols with size larger than $0.1 \mu \mathrm{m}$ decreased after being scrubbed, while the number concentration for aerosols smaller than $0.1 \mu \mathrm{m}$ increased. This indicated that the newly formed aerosols were mainly smaller than $0.1 \mu \mathrm{m}$ and the removed aerosols were mainly larger than $0.1 \mu \mathrm{m}$.

\subsection{Sulfuric acid aerosol removal by WESP}

3.2.1 Effects of residence time. Removal efficiencies of sulfuric acid aerosol under different residence time and applied voltages are shown in Fig. 3. The residence time was adjusted by changing the gas flow rate with 140,120, 100, 80 and $60 \mathrm{~m}^{3} \mathrm{~h}^{-1}$, respectively. As can be seen, the removal efficiency increased with the increasing residence time, dropping from 92.7 to $85.6 \%$ when the applied voltage was $32 \mathrm{kV}$. According to the Deutsch theory, ${ }^{\mathbf{1 0}}$ particle removal efficiency is positively correlated with particle migration velocity and is negatively correlated with gas flow rate under constant collection area. For given migration velocity, longer residence time leads to more particles transporting towards collection plates. ${ }^{23}$
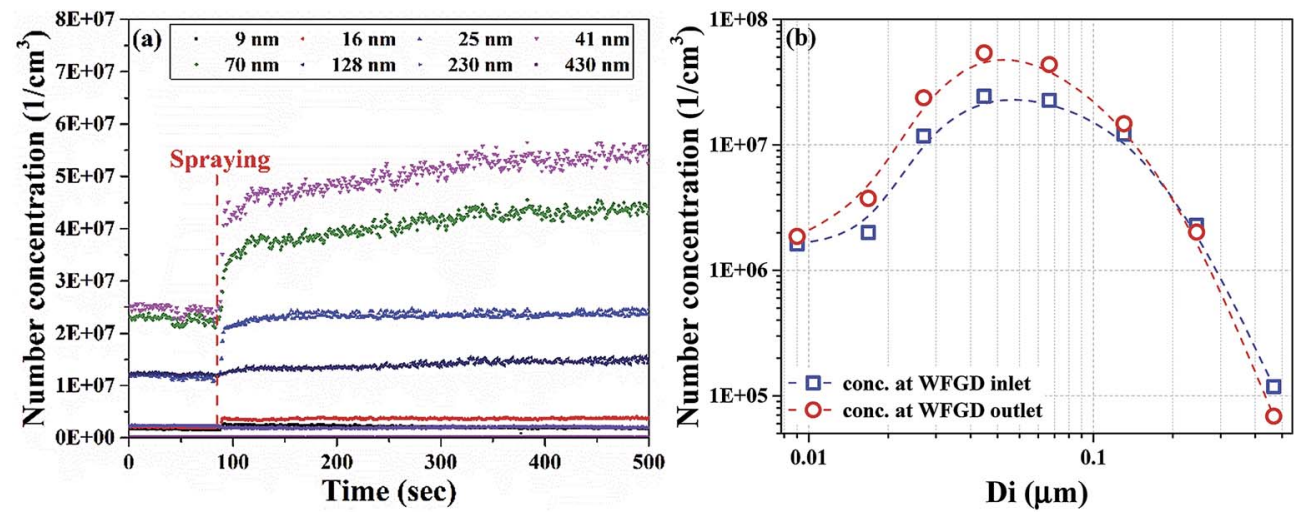

Fig. 2 Size distribution of sulfuric acid aerosol: (a) concentration evolution and (b) fractional concentration at inlet/outlet of WFGD. 


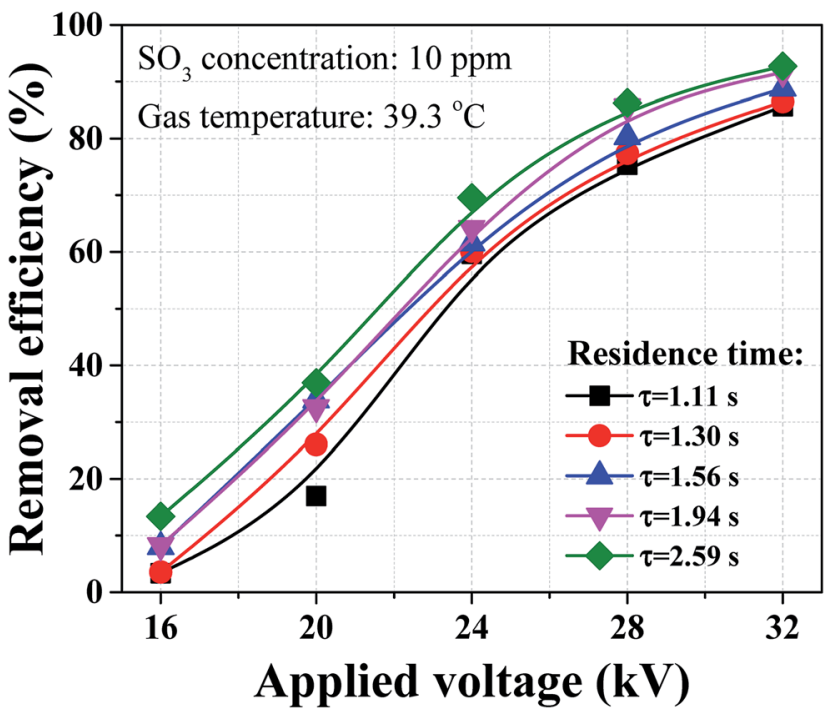

Fig. 3 Sulfuric acid aerosol removal under different residence time.

3.2.2 Effects of gas temperature. In coal-fired power plants, WESPs are installed downstream of WFGDs. Typical temperature range before WFGD is $90-120{ }^{\circ} \mathrm{C}$ and flue gas can be quenched to below $50{ }^{\circ} \mathrm{C}$ after WFGD process. In this paper, the flue gas temperature after WFGD was adjusted to 45.4, 43.2, 39.3, 37.8 and $35.1{ }^{\circ} \mathrm{C}$, respectively. Removal efficiencies of sulfuric acid aerosol under different gas temperature conditions are shown in Fig. 4. As can be seen, the removal efficiency increased with the decreasing gas temperature. The flue gas after WFGD is typically under saturation condition, and spontaneous phase transition could occur when supersaturated state is reached because of gas cooling. The condensable nature of sulfuric acid vapor makes it possible for the sulfuric acid aerosols to grow into larger ones by reducing gas temperature. Accumulative size distributions of sulfuric acid aerosol under different gas temperatures is shown in Fig. 5. The medium

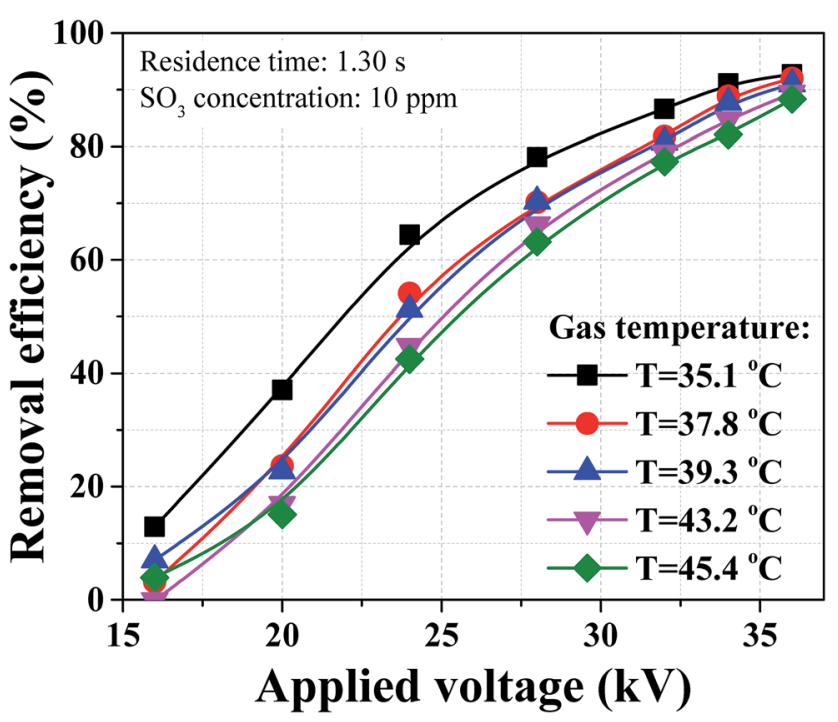

Fig. 4 Sulfuric acid aerosol removal under different gas temperatures.

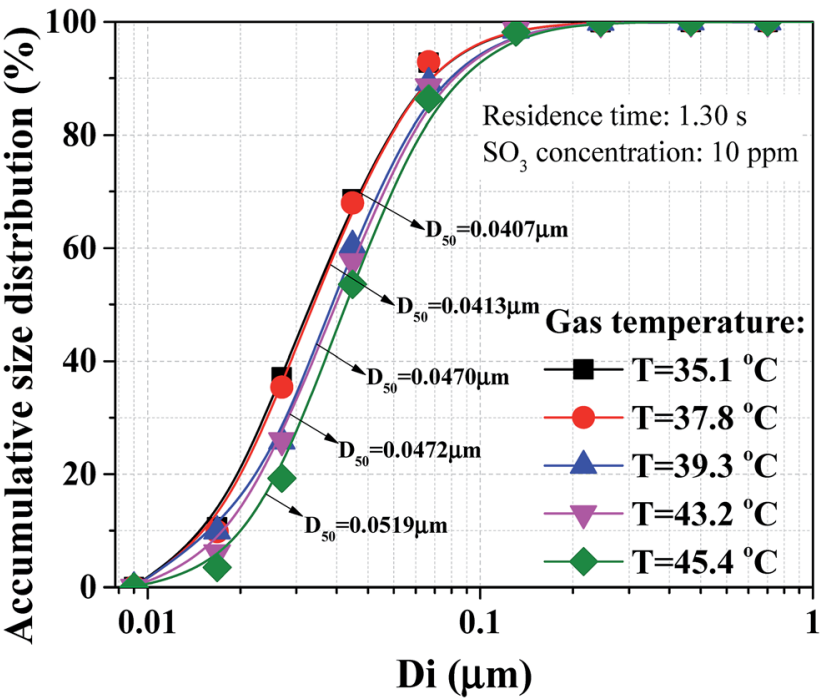

Fig. 5 Size distribution of sulfuric acid aerosol under different gas temperatures.

diameter $\left(D_{50}\right)$ increased by $27.5 \%$ when the gas temperature decreased from 45.4 to $35.1{ }^{\circ} \mathrm{C}$. Additionally, the decrease of gas temperature reduced gas flow rate, and the removal efficiency increased as discussed above for this reason as well.

3.2.3 Effects of $\mathrm{SO}_{3}$ concentration. In coal-fired power plants, about $1.5-3 \%$ of the sulfur content can be converted to $\mathrm{SO}_{3}$, and $\mathrm{SO}_{3}$ concentration after WFGD typically ranges from 10

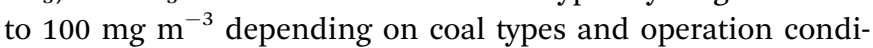
tion. Compared with dust, the impact of $\mathrm{SO}_{3}$ on the WESP operation is quite different. Current-voltage is a fundamental characteristic to evaluate WESP performance. Fig. 6 presents the current-voltage characteristics of the WESP under different $\mathrm{SO}_{3}$ concentrations. The corona current increased with the increasing voltage and $\mathrm{SO}_{3}$ had negative effects on corona discharge. The maximum corona current decreased from 0.79

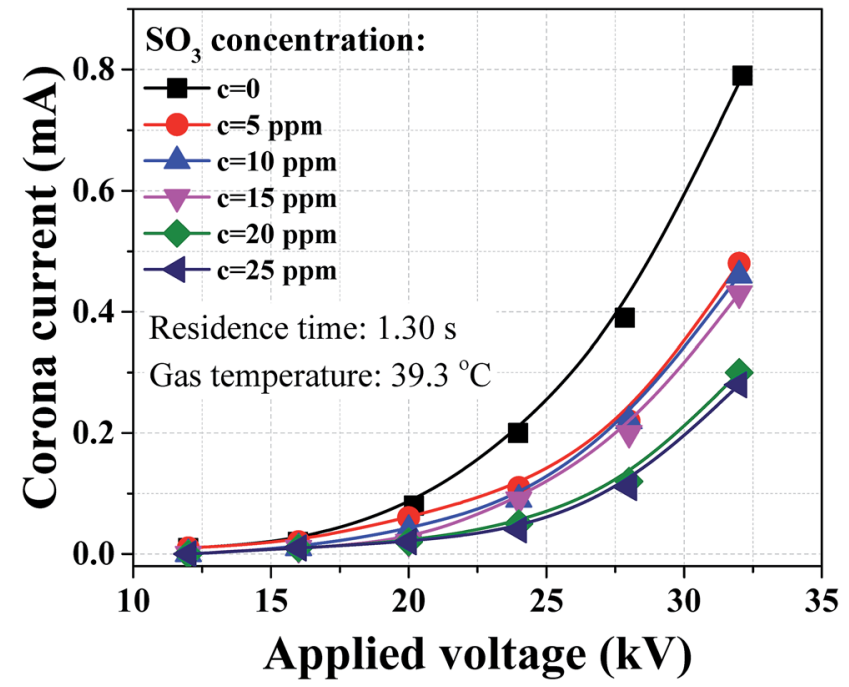

Fig. 6 Current-voltage characteristics under different $\mathrm{SO}_{3}$ concentrations. 
to $0.28 \mathrm{~mA}$ when $\mathrm{SO}_{3}$ concentration increased from 0 to $25 \mathrm{ppm}$. Corona current is mainly formed by the electrical mobility of free ions which deposits on the collection plate. ${ }^{24}$ As mentioned above, the number concentration of sulfuric acid aerosol was measured to be higher than $1 \times 10^{8} \mathrm{~cm}^{-3}$. The density of free ions will decrease when captured by fine particles. In addition, the charged aerosols can disturb the distribution of electric field, leading to lower ion production rates.

Dust removal efficiency usually increases as the inlet dust concentration increased, ${ }^{25,26}$ while the removal efficiency of sulfuric acid aerosol presented completely different results with similar concentration loadings as shown in Fig. 7. The removal efficiency of sulfuric acid aerosol decreased with the increasing $\mathrm{SO}_{3}$ concentration. As an example, when the applied voltage was $32 \mathrm{kV}$, the removal efficiency dropped from 91.0 to $87.3 \%$ with the $\mathrm{SO}_{3}$ concentration increasing from 5 to $25 \mathrm{ppm}$. The difference can be larger for lower applied voltage, and the removal efficiency dropped from 33.6 to $7.1 \%$ when the applied voltage was $16 \mathrm{kV}$. This phenomenon can be explained by the relationship between the corona discharge and particle charging. The above-mentioned corona current decreased with the increasing $\mathrm{SO}_{3}$ concentration, indicating the ion density in space decreased in the presence of $\mathrm{SO}_{3}$. Our previous numerical

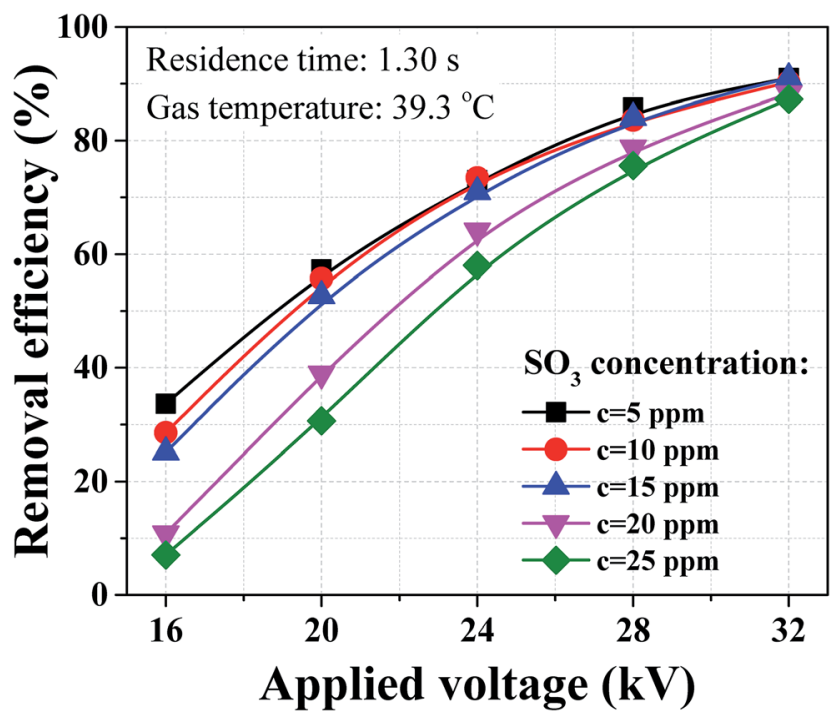

Fig. 7 Sulfuric acid aerosol removal under different $\mathrm{SO}_{3}$ concentrations. work $^{23}$ showed that the negative influence on the removal of sub-micron particle was more noticeable when reducing ion current. In industrial application, some WESPs can experience very high $\mathrm{SO}_{3}$ concentrations when dealing with high sulfur content fuels. These WESPs can be less effective, thereby some improvements were needed to improve the removal efficiency of sulfuric acid aerosol.

\subsection{Sulfuric acid aerosol removal by combined WESP}

As described above, the WESP performance deteriorated due to the reduction of corona current. In this paper, we proposed a novel perforated pre-charger to improve its performance for removal of sulfuric acid aerosol. A schematic configuration of the combined WESP is illustrated in Fig. 8a. Conventional precharger is merely an extension in length for the ESP, with similar wire-to-plate configuration but smaller discharge distance. In this paper, the proposed pre-charger takes full advantages of the air distribution plates at the inlet of the WESP, which consisted of spike-wires and two perforated plates as shown in Fig. 8b. The discharge electrode was connected with a high frequency power supply to generate ions for aerosol charging. The air distribution plates were used as grounded plate, and there are several benefits: (a) no extra installation space, (b) less SCA increase, and (c) higher turbulence intensity. The increased SCA due to the installation of pre-charger was only $0.67 \mathrm{~m}^{2}\left(\mathrm{~m}^{3} \mathrm{~s}^{-1}\right)^{-1}$, which can be neglected compared with that of WESP.

Flue gas was introduced into the pre-charger and thus sulfuric acid aerosol was negatively charged before entering the WESP. The pre-charger was primarily used for aerosol charging and the WESP was primarily used for aerosol collection. In the pre-charger, the distance from pin to plate was $25 \mathrm{~mm}$, which was much shorter than that in the WESP. Fig. 9 presents current-voltage characteristics of the pre-charger and the WESP. Similarly, the corona current of the pre-charger decreased significantly in the presence of $\mathrm{SO}_{3}$ (Fig. 9a), while the corona current of the WESP increased with the increasing pre-charger voltage (Fig. 9b). When aerosols passed through the pre-charger, they were charged and partly collected. That is, with the assistance of pre-charger, corona suppression mainly occurred in the pre-charger, and the corona discharge of WESP was significantly improved. Compared with the WESP, the current density on the perforated plates of the pre-charger was much higher. The maximum current densities were 16.03 and

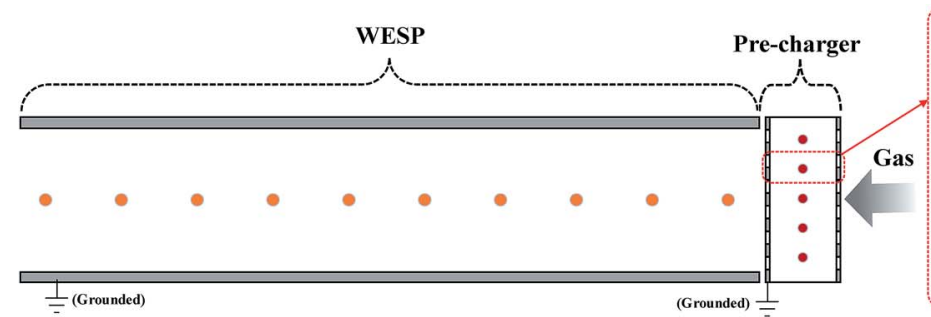

(a)

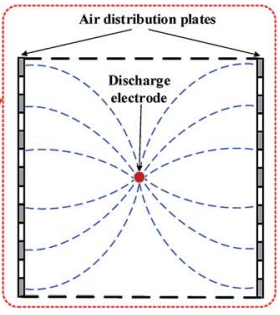

(b)

Fig. 8 Schematic of (a) the combined WESP and (b) the perforated pre-charger. 

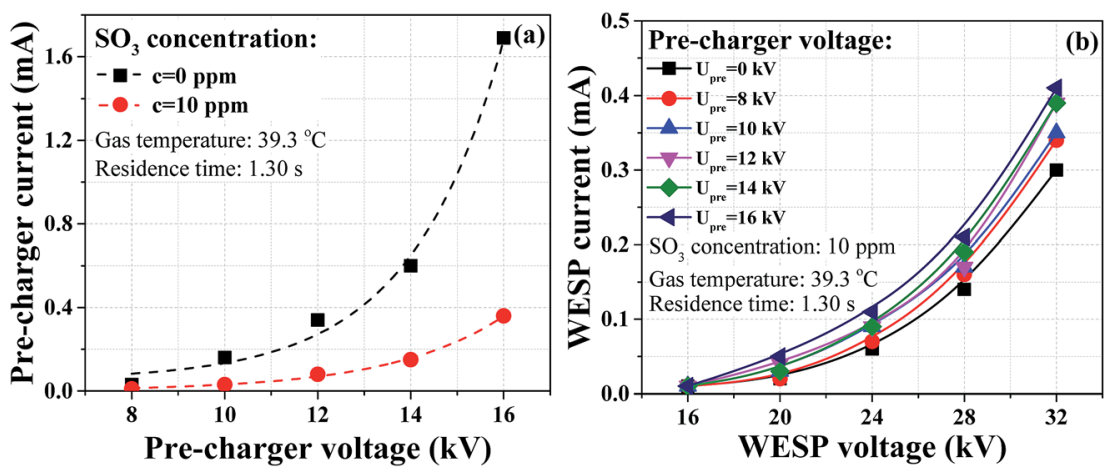

Fig. 9 Current-voltage characteristics of (a) pre-charger and (b) WESP.

$0.45 \mathrm{~mA} \mathrm{~m}^{-2}$ respectively for the pre-charger and the WESP when the $\mathrm{SO}_{3}$ concentration was $10 \mathrm{ppm}$.

Removal efficiencies of sulfuric acid aerosol under different pre-charger voltages are shown in Fig. 10. The performance of WESP was not good under low applied voltages, but the removal efficiency was significantly improved with the assistance of precharger. As an example, when the WESP voltage was $16 \mathrm{kV}$, the removal efficiency increased from 27.9 to $82.4 \%$ as the precharger voltage increased from 0 to $16 \mathrm{kV}$. The key reason was that the pre-charger provided sufficient ions for aerosol charging even though the WESP operated under low applied

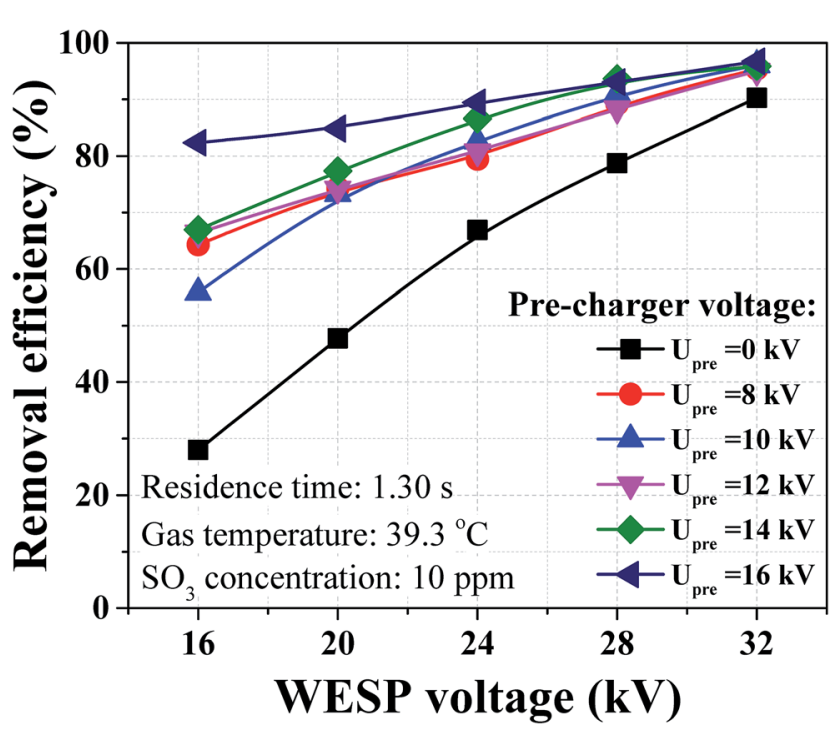

Fig. 10 Sulfuric acid aerosol removal under different pre-charger voltages. voltage. The removal efficiency can be as high as $95.8 \%$ when the pre-charger and the WESP both operated under maximum applied voltages. The WESP and combined WESP (WESP + precharger) are compared in Table 1. For the WESP only, increasing SCA can achieve the same removal efficiency with the combined WESP. Namely, the overall SCA can be reduced by using the precharger. As an example, the overall SCA was reduced from 28.80 to $22.27 \mathrm{~m}^{2}\left(\mathrm{~m}^{3} \mathrm{~s}^{-1}\right)^{-1}$ when the pre-charger voltage was $8 \mathrm{kV}$.

Furthermore, the fractional removal efficiencies of sulfuric acid aerosol with pre-charger on and off are compared in Fig. 11. The fractional removal efficiency curves had similar tendencies for the two cases. For aerosols with diameter less than $0.03 \mu \mathrm{m}$, the removal efficiency decreased significantly with the decreasing aerosol diameter. For aerosols with diameter larger than $0.03 \mu \mathrm{m}$, there existed a minimum removal efficiency for aerosols with diameters about $0.1 \mu \mathrm{m}$. This phenomenon was attributed to the size dependence of particle charging and electrical mobility. Inside an ESP, particles are charged by field charging and diffusion charging effects. Field charging is dominant for particles larger than $1.0 \mu \mathrm{m}$ and diffusion charging is dominant for particles smaller than $0.1 \mu \mathrm{m}$, respectively.$^{10}$ The electrical mobility for aerosols with diameters about $0.1 \mu \mathrm{m}$ was small because of the two charging effects, which accounts for the minimum removal efficiency in this size range. For particles smaller than $0.03 \mu \mathrm{m}$, some of them cannot be charged due to the partial charging effect, resulting in a decrease of collection efficiency. ${ }^{27}$ The WESP performance for removal of sulfuric acid aerosol was improved assisted with pre-charger. The improvement is more noticeable for aerosols in the range from 0.03 to $0.5 \mu \mathrm{m}$ because the substantial increase of electrical mobility in this range.

Table 1 Comparison of two WESPs under different conditions

\begin{tabular}{|c|c|c|c|c|c|}
\hline \multirow[t]{3}{*}{ WESP } & 21.60 & 32 & 0 & $90.3 \%$ & Exp. \\
\hline & 24.30 & 32 & 0 & $92.7 \%$ & Predicted $^{a}$ \\
\hline & 28.80 & 32 & 0 & $95.5 \%$ & \\
\hline Combined WESP & 22.27 & 32 & 8 & $95.4 \%$ & Exp. \\
\hline
\end{tabular}

${ }^{a}$ The prediction was done with the Deutsch equation. 


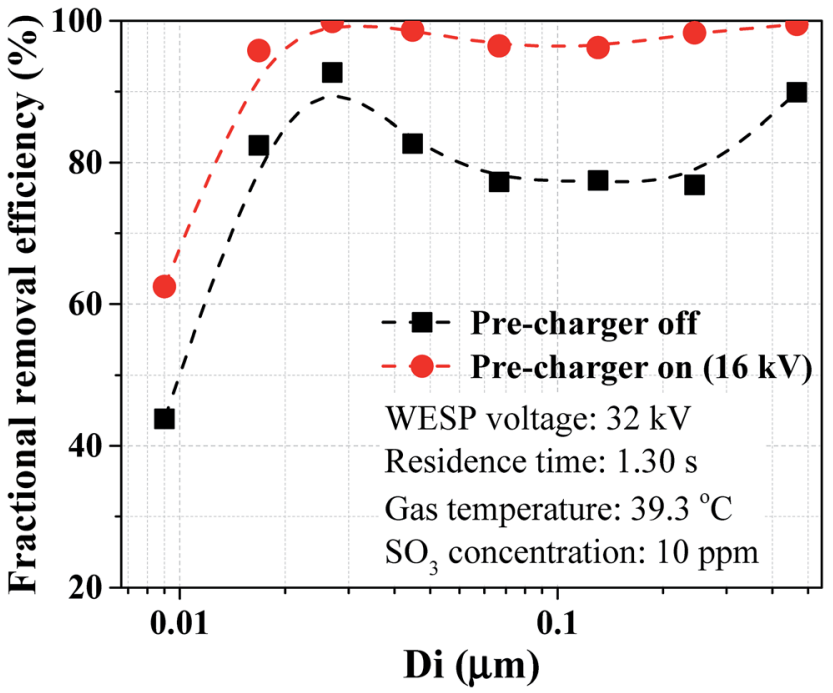

Fig. 11 Fractional removal efficiency of sulfuric acid aerosol with precharger on and off.

A heat exchanger was installed downstream the WFGD to further improve the removal efficiency of sulfuric acid aerosol since the removal efficiency was influenced by flue gas temperature. With the application of heat exchanger, the gas temperature could be cooled down from 43.2 to $39.1{ }^{\circ} \mathrm{C}$. Removal efficiencies and emissions of sulfuric acid aerosol in three operation cases are compared in Fig. 12. The sulfuric acid aerosol was removed by WESP with an efficiency of $90.3 \%$, and the efficiency was improved to $95.8 \%$ assisted with pre-charger. Moreover, the removal efficiency could be further improved to $97.8 \%$ assisted with pre-charger and heat exchanger at the same time. As can be seen from Fig. 12, emissions of sulfuric acid aerosol can reach different levels in different cases. In case 2, the emission concentration of sulfuric acid aerosol was lower than $2 \mathrm{mg} \mathrm{m}^{-3}$, and it could be lower than $1 \mathrm{mg} \mathrm{m}^{-3}$ in case 3 with the assistance of pre-charger and heat exchanger. In real

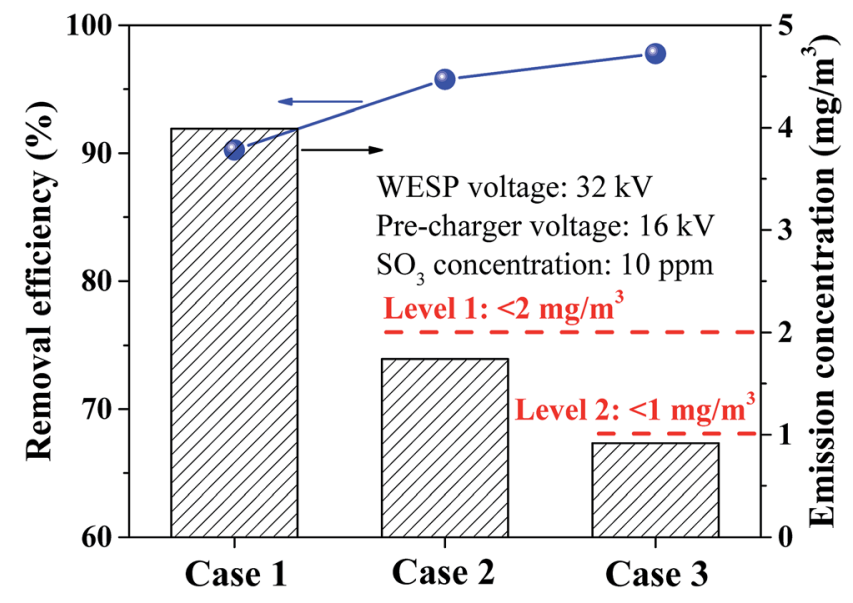

Fig. 12 Comparison of sulfuric acid aerosol removal for different cases (case 1: WESP, case 2: WESP + pre-charger, and case 3: WESP + pre-charger + heat exchanger). application, technologies can be determined based on the emission requirements of sulfuric acid aerosol.

\section{Conclusions}

In this study, a WESP assisted with novel pre-charger was proposed to efficiently remove sulfuric acid aerosol from flue gases. Parameters including residence time, gas temperature and $\mathrm{SO}_{3}$ concentration were investigated experimentally without any enhanced methods. The number concentration of sulfuric acid aerosol after WFGD amounted to higher than $1 \times$ $10^{8} \mathrm{~cm}^{-3}$ with diameter smaller than $0.1 \mu \mathrm{m}$. Sulfuric acid aerosols can be enlarged by decreasing gas temperature. The medium diameter increased by $27.5 \%$ when the gas temperature decreased from 45.4 to $35.1^{\circ} \mathrm{C}$, leading to higher removal efficiency of sulfuric acid aerosol. The corona discharge and removal efficiency were both suppressed with the increasing $\mathrm{SO}_{3}$ concentration. The maximum corona current was reduced from 0.79 to $0.28 \mathrm{~mA}$ when $\mathrm{SO}_{3}$ concentration increased from 0 to $25 \mathrm{ppm}$, and the corresponding maximum removal efficiency dropped from 91.0 to $87.3 \%$. A novel perforated precharger was proposed to further improve the removal efficiency of sulfuric acid aerosol with less increased SCA. Both the corona discharge and removal efficiency of the WESP were improved after application of the pre-charger. The removal efficiency could be improved to $95.8 \%$ when the WESP applied voltage was $32 \mathrm{kV}$ and pre-charger voltage was $16 \mathrm{kV}$, and the emission concentration was lower than $2 \mathrm{mg} \mathrm{m}^{-3}$. A heat exchanger was proposed as an option to enhance the removal efficiency. With application of the heat exchanger, the removal efficiency of the combined WESP could be further improved to $97.8 \%$, and the corresponding emission concentration could be lower than $1 \mathrm{mg} \mathrm{m}^{-3}$.

\section{Conflicts of interest}

There are no conflicts to declare.

\section{Acknowledgements}

This work was supported by National Key Research and Development Program of China (No. 2017YFB0603201), Environmental Welfare Project of Ministry of Environmental Protection of China (No. 201509012), National Natural Science Foundation of China (U1609212), Science and Technology Development Project of Shandong Province (No. 2014GJJS0501).

\section{References}

1 R. K. Srivastava, C. A. Miller, C. Erickson and R. Jambhekar, Emissions of sulfur trioxide from coal-fired power plants, $J$. Air Waste Manage. Assoc., 2004, 54, 750-762.

2 D. Pan, L. Yang, H. Wu and R. Huang, Removal characteristics of sulfuric acid aerosols from coal-fired power plants, J. Air Waste Manage. Assoc., 2017, 67, 352-357.

3 Y. Cao, H. Zhou, W. Jiang, C. W. Chen and W. P. Pan, Studies of the fate of sulfur trioxide in coal-fired utility boilers based 
on modified selected condensation methods, Environ. Sci. Technol., 2010, 44, 3429-3434.

4 S. City, Integrated Emission Standard for Air Pollutants, 2016.

$5 \mathrm{H}$. Fujishima and C. Nagata, Experiences of wet type electrostatic precipitator successfully applied for $\mathrm{SO}_{3}$ removal in boilers using high sulfur content fuel, Ninth International Conference on Electrostatic Precipitation, Kruger Gate, South Africa, 2004.

$6 \mathrm{~W}$. Buckley and B. Altshuler, Sulfuric acid mist generation in utility boiler flue gas, Power Eng., 2002, 11, 132-136.

7 Y. S. Xu, X. W. Liu, J. Cui, D. Chen, M. H. Xu, S. W. Pan, et al., Field measurements on the emission and removal of $\mathrm{PM}_{2.5}$ from coal-fired power stations: 4. PM removal performance of wet electrostatic precipitators, Energy Fuels, 2016, 30, 7465-7473.

8 S. Sinanis, A. Wix, L. Ana and K. Schaber, Characterization of sulphuric acid and ammonium sulphate aerosols in wet flue gas cleaning processes, Chem. Eng. Process., 2008, 47, 22-30.

9 H. Wu, D. Pan, J. Bao, Y. Jiang, G. Hong, B. Yang, et al., Improving the removal efficiency of sulfuric acid droplets from flue gas using heterogeneous vapor condensation in a limestone-gypsum desulfurization process, J. Chem. Technol. Biotechnol., 2017, 92, 230-237.

10 K. R. Parker, Applied electrostatic precipitation, Springer Science \& Business Media, 2012.

11 A. Mizuno, Electrostatic precipitation, IEEE Trans. Dielectr. Electr. Insul., 2000, 7, 615-624.

12 Q. Du, L. P. Su, H. M. Dong, J. M. Gao, Z. F. Zhao, D. H. Lv, et al., The experimental study of a water-saving wet electrostatic precipitator for removing fine particles, $J$. Electrost., 2016, 81, 42-47.

13 T. M. Chen, C. J. Tsai, S. Y. Yan and S. N. Li, An efficient wet electrostatic precipitator for removing nanoparticles, submicron and micron-sized particles, Sep. Purif. Technol., 2014, 136, 27-35.

14 L. Dey and C. Venkataraman, A wet electrostatic precipitator (WESP) for soft nanoparticle collection, Aerosol Sci. Technol., 2012, 46, 750-759.

15 S. H. Jeong, S. H. Shim, D. K. Song, W. S. Hong, J. H. Hong and S. S. Lee, Performance of a pilot-scale wet electrostatic precipitator for the control of sulfuric acid mist and fine particulates, Pol. J. Environ. Stud., 2013, 22, 409-415.

16 J. C. Chang, Y. Dong, Z. Q. Wang, P. Wang, P. Chen and C. Y. Ma, Removal of sulfuric acid aerosol in a wet electrostatic precipitator with single terylene or polypropylene collection electrodes, J. Aerosol Sci., 2011, 42, 544-554.

17 J. P. Yan, L. Q. Chen and L. J. Yang, Combined effect of acoustic agglomeration and vapor condensation on fine particles removal, Chem. Eng. J., 2016, 290, 319-327.

18 D. Zhou, Z. Y. Luo, J. P. Jiang, H. Chen, M. S. Lu and M. X. Fang, Experimental study on improving the efficiency of dust removers by using acoustic agglomeration as pretreatment, Powder Technol., 2016, 289, 52-59.

19 Y. Liu, B. Hu, L. Zhou, Y. Z. Jiang and L. J. Yang, Improving the removal of fine particles with an electrostatic precipitator by chemical agglomeration, Energy Fuels, 2016, 30, 8441-8447.

20 Q. Chang, C. Zheng, Z. Yang, M. Fang, X. Gao, Z. Luo, et al., Electric agglomeration modes of coal-fired fly-ash particles with water droplet humidification, Fuel, 2017, 200, 134-145.

21 R. C. Staehle, R. J. Triscori, K. S. Kumar, G. Ross and R. Cothron, Wet electrostatic precipitators for high efficiency control of fine particulates and sulfuric acid mist, Institute of Clean Air Companies (ICAC) Forum, 2003.

22 H. J. Kim, B. Han, Y. J. Kim, K. D. Hwang, W. S. Oh, S. Y. Yoo, et al., Fine particle removal performance of a two-stage wet electrostatic precipitator using a nonmetallic pre-charger, J. Air Waste Manage. Assoc., 2011, 61, 1334-1343.

23 Q. Y. Lu, Z. D. Yang, C. H. Zheng, X. Li, C. Zhao, X. Xu, et al., Numerical simulation on the fine particle charging and transport behaviors in a wire-plate electrostatic precipitator, Adv. Powder Technol., 2016, 27, 1905-1911.

24 R. B. Michael, Wet ESP for the collection of submicron particles mist and air toxics, 11th International Conference on Electrostatic Precipitation, Hangzhou, 2008.

25 Z. Yang, C. Zheng, Q. Chang, Y. Wan, Y. Wang, X. Gao, et al., Fine particle migration and collection in a wet electrostatic precipitator, J. Air Waste Manage. Assoc., 2017, 67, 498-506.

26 A. Bologa, H. R. Paur, M. Lehner, H. Seifert, T. Wascher and K. Woletz, Collection of fine particles by novel wet electrostatic precipitator, IEEE Trans. Ind. Appl., 2009, 45, 2170-2177.

27 G. Y. Lin, T. M. Chen and C. J. Tsai, A modified deutschanderson equation for predicting the nanoparticle collection efficiency of electrostatic precipitators, Aerosol Air Qual. Res., 2012, 12, 697-706. 